\title{
DISPUTAS DE SENTIDOS: DAS BASES CUR- RICULARES ÀS ÁREAS DE ATUAÇÃO EM RELAÇÕES PÚBLICAS
}

ELISANGELA CARLOSSO MACHADO MORTARI UNIVERSIDADE FEDERAL DE SANTA MARIA SANTA MARIA, RIO GRANDE DO SUL, BRASIL ELIMORTARI@GMAIL.COM

JOZENE NOAL DE OLIVEIRA UNIVERSIDADE FEDERAL DE SANTA MARIA SANTA MARIA, RIO GRANDE DO SUL, BRASIL JOZENENOAL@HOTMAIL.COM 


\section{DISPUTAS DE SENTIDOS: DAS BASES CURRICULARES ÀS ÁREAS DE ATUAÇÃO EM RELAÇÕES PÚBLICAS}

Resumo: $O$ texto é resultado de um estudo realizado com os egressos do curso de Relações Públicas da UFSM e apresenta dados que problematizam a circulação dos sentidos acerca das áreas de atuação do profissional de Relações Públicas. Também discute as matrizes curriculares e suas implicações na formação profissional, alinhando as falas dos profissionais egressos com as ofertas pedagógicas da academia. Vislumbra ainda o empoderamento do exercício pedagógico e profissional.

\section{INTRODUÇÃO}

Os estudos sobre as matrizes curriculares em Relações Públicas datam da década de 60 quando o ensino de Comunicação Social, em nível de graduação, foi regido por um currículo mínimo homologado pelo Ministério de Educação - MEC (MOURA, 2002). Neste período há o entendimento da atividade enquanto profissão e decorre daí sua necessidade de sistematização segundo as lógicas do lugar acadêmico. Ainda nessa fase iniciam as aproximações das demandas do mercado e as disputas de sentidos entre a formação em Relações Públicas voltada ou ao campo da comunicação ou ao campo da administração. Essa indefinição é percebida na construção da identidade profissional e deflagrada em grande parte pela sistematização curricular. Quando o CONFERP solicita, ainda em 1977 a aproximação com a área de administração e o Ministério da Educação repudia o pedido argumentando que e manutenção da proximidade com o campo da comunicação deve-se ás atribuições do profissional de Relações Públicas (RP) dialogarem melhor com disciplinas da Comunicação Social, faz-se uma modelagem das áreas de atuação e do perfil profissional em RP. A indefinição pode ser diagnosticada já nas competências que o ambiente acadêmico delega ao profissional que ora tem habilidade (bacharel em Comunicação Social com habilitação para Relações Públicas), ora tem gerência (no elenco de disciplinas de gestão), ora tem competência para práticas originárias da área (como descrito nos documentos regulatórios dos cursos de graduação). A divisão nuclear proposta pela matriz curricular para resolver essa indefinição precisa dar conta, portanto, das necessidades de um mercado em formação, dos saberes reunidos em programas disciplinares, dos diálogos entre as áreas de formação (geralmente jornalismo, publicidade e relações púbicas) e das competências para o entendimento de qual é a atividade fim do profissional 
de Relações Públicas.

O paradigma das habilitações colabora para esse encaminhamento da divisão em núcleos de saberes quando descreve as habilidades da área através de disciplinas tecnicistas e da prática empregada pelo estágio obrigatório. Através da habilitação para a exercício das Relações Públicas garante-se a performance esperada pelo perfil profissional formado na academia e acoIhido pelo mercado de trabalho. Como se vê, "é necessário um corpo teórico de conhecimentos, ou seja, na linguagem acadêmica, um corpus doctrinae que sustente sua existência e possa orientar em um único sentido o exercício profissional dessa atividade" (FERRARI, 2009, p. 138). Com essa reflexão acerca da matriz curricular e da área de atuação é que se questiona qual é o espaço de legitimação das Relações Públicas na estrutura organizacional e na sociedade? Para Rüdiger apud MOURA e FOSSATTI (2011, p.42) "as relações públicas lograram se organizar profissionalmente, mas ainda estão longe de poder dizer que se legitimaram socialmemte.” Deduz-se, dessa forma, que há um hiato entre a organização profissional, a organização social, a organização mercadológica e a organização curricular no entendimento das Relações Públicas.

Soma-se a esse cenário o olhar tecnicista e racional tão duramente criticado na construção das matrizes curriculares e que tem se sobreposto a visão crítica e dialogada recomendada pelos pesquisadores da área educacional. Por isso, a discussão sobre o posicionamento das Universidades na formação do profissional em Relações Públicas se mantêm atual. É necessário dar corpo a estudos que discutam o papel da academia e a ação do mercado na legitimação da área frente às demandas políticas, sociais, econômicas e culturais onde se encontram os candidatos à profissão. Acrescenta-se o ambiente público para o ensino das Relações Públicas e a implantação das novas diretrizes curriculares que força o planejamento visando às atividades específicas das áreas profissionais reforçando a tendência técnico-linear.

\section{MUITOS SENTIDOS PARA AS RELAÇÕES PÚBLICAS}

Através da abordagem das teorias da comunicação, disciplina presente no núcleo de formação para Relações Públicas, é possível compreender o caráter manipulador presente na prática desta profissão quando se propõem a gerenciar os conteúdos de interesse dos públicos e o caráter persuasivo 
que ultrapassa o ambiente de consultoria construído entre as organizações e o domínio público das informações. Vem daí a defesa da comunicação como base para o pensamento acerca das Relações Públicas. Dessa forma, desenha-se um cenário que pretende compreender a dinâmica pedagógica das Relações Públicas em circuitos que promovam os estudos em diagnósticos internos às organizações, em auditorias externas, na classificação e no entendimento comportamental e psicológico dos públicos, no relacionamentos entre os sujeitos sociais, no desenvolvimento de estratégias organizacionais, na promoção da cultura, nos processos de percepção que levam a formação de imagens mentais e sensoriais e na análise de situações políticas, econômicas e sociais.

O campo científico que protege as especificidade de uma área de conhecimento deve ser compreendido em Relações Públicas a partir de seus saberes específicos, como os descritos acima, e construídos pelos seus pares e sua comunidade acadêmica. Assim, disciplinas como teorias das Relações Públicas e comunicação organizacional atendem parcialmente a constituição de um campo teórico próprio, revisitando demandas curriculares e provocando discussões e avanços na área. FERRARI (2009) defende que no Brasil foi o pesquisador Porto Simões que apresentou uma teoria da função organizacional política das Relações Públicas, constituindo a área de saber como um espaço científico. Segundo a autora, "ao lado de Porto Simões, as demais definições são classificadas como descritivas, funcionais e operacionais, limitando-se à exposição de técnicas e de propriedades midiáticas e no ‘como fazer' e não no 'ser' da atividade” (p.136). Entende-se, portanto a atividade das relações públicas no âmbito da esfera pública, como descrito por HABERMAS (1984), no que tange a vertente essencialmente política das relações públicas e sua atuação nas disputas de poderes. Isso significa que as orientações pedagógicas devem considerar as dinâmicas e as modificações sociais, demorando o olhar sobre os interesses públicos. Por isso a demanda de conhecimentos como os desenvolvidos em relações públicas e suas interfaces com as instâncias e as instituições públicas.

\section{REPENSAR AS RELAÇÕES PÚBICAS ATRAVÉS dA AVALIAÇÃo de SUAS PRÁTICAS PROFISSIONAIS E ACADÊMICAS}

O aumento na oferta de vagas em cursos superiores de Relações Públicas força pensar sobre as orientações pedagógicas mediante os contextos existenciais dos futuros profissionais que atuarão em mercados de comuni- 
cação locais, ou seja, na região de abrangência das Instituições formadoras dos recursos humanos. Ademais, considerando o caráter público das Universidades e a cultura regional que caracteriza sua identidade institucional cabe avaliar como os sentidos acerca da profissão e a construção das áreas de atuação passam a ser deflagrados.

Nos últimos dez anos o Rio Grande do Sul contabilizou três cursos de graduação em relações públicas ofertados em Instituições Federais e em cidades com até 250 mil habitantes no interior do Estado. Os significados implicados nesta oferta podem ser visualizados na evasão dos ingressantes e na evasão dos concluintes: os que iniciam a graduação em Relações Públicas encontram uma linearidade do pensamento acadêmico dissonante com suas expectativas, por outro lado os egressos, grosso modo, não visualizam no mercado as áreas de atuação prospectadas durante a formação acadêmica.

Essa visão impele para o desenvolvimento de estudos que deem conta de uma realidade que atravessa o campo do conhecimento em comunicação e relações públicas: um campo marcado ainda por incertezas e indefinições e que exigem um pensamento transversal acerca das aplicações e práticas das relações públicas. A realização de um estudo ontológico que questiona valores, conceitos e métodos deve, segundo CHAUí (2008), partir de um recorte do cotidiano:

\footnotetext{
Quando aquilo que faz parte de nossa vida cotidiana se torna problemático, estranho, confuso; quando somos surpreendidos pelas coisas e pelas pessoas, porque acontece algo inesperado ou imprevisível; quando desejamos usar certas coisas e não sabemos lidar com elas; enfim, quando o significado costumeiro das coisas, das ações, dos valores ou das pessoas perde sentido ou se mostra obscuro e confuso, ou quando o que nos foi dito, ensinado e transmitido sobre eles já não nos satisfaz e queremos saber mais e melhor. (CHAUÍ, p. 205)
}

Partindo desse enquadramento filosófico e metodológico foi iniciado em 2014 um estudo intitulado "Relações que são públicas: projeto de relacionamento e avaliação dos egressos do curso de Relações Públicas da UFSM" com o objetivo de mapear os egressos do curso e triangular os resultados com os principais conteúdos curriculares acionados pelos profissionais da área no mercado de trabalho. O objetivo inicial deste trabalho partiu da necessidade de reconhecer as redes que se tecem no momento em que 
o acadêmico deixa a universidade, além de avaliar a prática profissional segundo as linhas traçadas no projeto político pedagógico do curso. A fim de confrontar as expectativas dos atores envolvidos no cenário das Relações Públicas foram geradas categorias que permitissem visualizar as estratégias pedagógicas previstas pelo PPC do curso na função prática desempenhada pelo egresso. Foram entrevistados treze profissionais egressos, com foco na articulação do Projeto Pedagógico do Curso (PPC) e na função exercida pelos RP's no ambiente profissional. A captação ocorreu nos formatos de áudio e vídeo, gerando uma série de programetes e podcasts.

Figura 01: Marca da vinheta de abertura do programa e entrevistadas da primeira temporada em seus respectivos locais de trabalho.

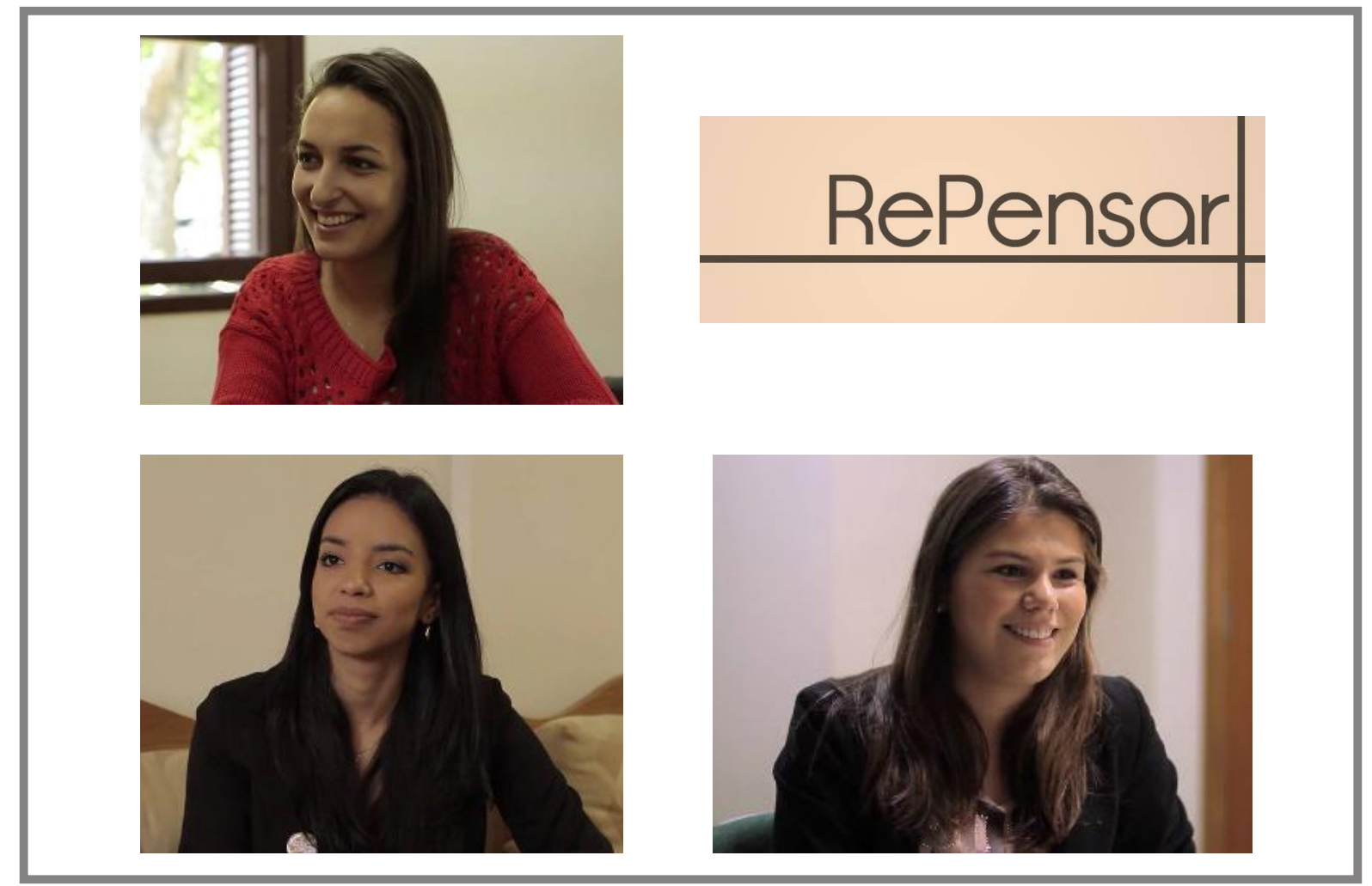

Na segunda temporada do projeto, em 2015, categorizaram-se as falas obtidas com o objetivo de mapear as disciplinas mais importantes para a atuação dos profissionais no mercado de trabalho, confrontando-as com as áreas de atuação descritas no documento que regulamenta pedagógica e academicamente a formação dos Relações Públicas na Instituição, conforme mostra a tabela abaixo. 
Tabela 01 - Áreas de atuação em Relações Públicas. PPC Curso de Comunicação Social Relações Públicas, 2014.

\begin{tabular}{|l|l|}
\hline 01 & Planejamento de estratégias de comunicação em empresas privadas; \\
\hline 02 & Planejamento de estratégias de comunicação em empresas governamentais; \\
\hline 03 & Planejamento de estratégias de comunicação em empresas do Terceiro Setor; \\
\hline 04 & $\begin{array}{l}\text { Realização de pesquisas de opinião, de imagem, de mercado e de clima organi- } \\
\text { zacional; }\end{array}$ \\
\hline 05 & Planejamento e produção de peças gráficas; \\
\hline 06 & Planejamento e produção de fotos; \\
\hline 07 & Planejamento e produção de vídeos e áudios institucionais; \\
\hline 08 & Planejamento de eventos; \\
\hline 09 & Gestão de projetos culturais; \\
\hline 10 & Gestão de projetos sociais; \\
\hline 11 & Gerenciamento da imagem empresarial; \\
\hline 12 & Assessoria e consultoria de comunicação; \\
\hline 13 & Assessoria de comunicação/imprensa; \\
\hline 14 & Administração de crises; \\
\hline 15 & Pesquisador científico na área da comunicação; \\
\hline 16 & Planejamento de estratégias de comunicação de empresas privadas; \\
\hline
\end{tabular}

A partir das entrevistas realizadas na primeira temporada foram formuladas questões específicas para nove egressos perfilados em diferentes áreas de atuação da profissão. Esse método foi escolhido porque

\footnotetext{
"quando interagimos através da linguagem (...), temos sempre objetivos, fins a serem atingidos: há relações que desejamos estabelecer, efeitos que pretendemos causar, comportamentos que queremos ver desencadeados, isto é, pretendemos atuar sobre $\mathrm{o}(\mathrm{s})$ outro(os) de determinada maneira, obter dele(s) determinadas reações" (KOCH, 1998, p. 29)
}

Através da técnica de entrevista para audiovisual há o estabelecimento da auto-referencialidade, ou seja, o profissional egresso passa a ser o sujeito comunicante da experiência e faz referências, num processo simbólico, a si mesmo. Nessa dinâmica, o entrevistado estabelece topologias que colocam em evidência aspectos da sua formação acadêmica, pessoal e profissional. A abordagem que mapeou os espaços que as Relações Públicas ocupam após o lugar institucional e acadêmico pode ser visualizado na relação estabele- 
cida entre a questão formulada para o egresso e objetivo de escuta da sua fala:

\section{Tabela 02 - Roteiro de Entrevista}

\begin{tabular}{|c|c|}
\hline Projeto RePensar & Finalidades/Objetivos \\
\hline $\begin{array}{l}\text { Por que você escolheu o curso de Relações } \\
\text { Públicas da UFSM? }\end{array}$ & $\begin{array}{l}\text { Avaliar do perfil do egresso de Relações } \\
\text { Públicas bem como a imagem do curso na } \\
\text { avaliação do aluno ingressante. }\end{array}$ \\
\hline $\begin{array}{l}\text { Foi durante a graduação em Relações } \\
\text { Públicas que você decidiu por atuar na área } \\
\text { de } \quad \text { ? }\end{array}$ & $\begin{array}{l}\text { Compreender se a graduação oferece sub- } \\
\text { sídio para a escolha da área de trabalho es- } \\
\text { pecífica. }\end{array}$ \\
\hline $\begin{array}{l}\text { Foi necessário fazer cursos complementa- } \\
\text { res para suprir as necessidades da atuação } \\
\text { em }\end{array}$ & $\begin{array}{l}\text { Analisar as demandas das áreas de Relações } \\
\text { Públicas e refletir sobre as oportunidades } \\
\text { oferecidas no período da graduação. }\end{array}$ \\
\hline $\begin{array}{l}\text { A sua formação em Relações Públicas foi } \\
\text { satisfatória? O preparou para o mercado } \\
\text { profissional? }\end{array}$ & $\begin{array}{l}\text { Verificar se a graduação atingiu as expecta- } \\
\text { tivas do egresso assim como deu subsídio } \\
\text { para o mercado profissional. }\end{array}$ \\
\hline $\begin{array}{l}\text { Cite algumas disciplinas que você avalia } \\
\text { como essenciais para a formação na área } \\
\text { de }\end{array}$ & $\begin{array}{l}\text { Investigar as disciplinas que foram essenci- } \\
\text { ais para a atuação nas áreas entrevistadas, } \\
\text { abrindo oportunidade para o aperfeiçoa- } \\
\text { mento do currículo. }\end{array}$ \\
\hline $\begin{array}{l}\text { Para atuar na área de } \ldots \text { há a neces- } \\
\text { sidade da formação em Relações Públi- } \\
\text { cas? (Você conhece situações onde outros } \\
\text { profissionais que não tem a formação em } \\
\text { RP, exercem a sua atividade atual?). }\end{array}$ & $\begin{array}{l}\text { Avaliar a valorização da formação acadêmi- } \\
\text { ca para esses profissionais, bem como o } \\
\text { campo de trabalho e os concorrentes. }\end{array}$ \\
\hline $\begin{array}{l}\text { O que você incluiria na estrutura curricu- } \\
\text { lar do curso considerando sua experiência } \\
\text { profissional? }\end{array}$ & $\begin{array}{l}\text { Aproximar a experiência do mercado de } \\
\text { trabalho à academia. Dar subsídio para } \\
\text { possíveis ações de reformulação curricular, } \\
\text { criando estratégias pedagógicas através } \\
\text { da vivência no mercado de trabalho. }\end{array}$ \\
\hline $\begin{array}{l}\text { Como você avalia a experiência profission- } \\
\text { al dos professores durante a graduação em } \\
\text { Relações Públicas? }\end{array}$ & $\begin{array}{l}\text { Avaliar as experiências práticas dos profes- } \\
\text { sores que resultam na didática empregada } \\
\text { para a transmissão de conhecimentos e at- } \\
\text { ualização das técnicas. }\end{array}$ \\
\hline $\begin{array}{l}\text { O vínculo com a UFSM (ter seu diploma } \\
\text { pela UFSM) resultou maiores oportuni- } \\
\text { dades no mercado de trabalho? }\end{array}$ & $\begin{array}{l}\text { Perceber qual a influência da imagem da } \\
\text { UFSM no mercado de trabalho. }\end{array}$ \\
\hline $\begin{array}{l}\text { Onde você atua, há quanto tempo? Quais } \\
\text { outras experiências profissionais você já } \\
\text { teve depois de formado? }\end{array}$ & $\begin{array}{l}\text { Apresentar a área de atuação do egresso } \\
\text { e sondar sobre as oportunidades de tra- } \\
\text { balho, observando outras experiências de- } \\
\text { pois de formado. }\end{array}$ \\
\hline
\end{tabular}

Os egressos, a partir de suas experiências profissionais, avaliaram o elenco das disciplinas do Projeto Político Pedagógico- PPC correspondente ao 
seu ano de graduação $(1987 ; 2004 ; 2010)$ bem como o do atual PPC (2014), baseando-se nas ementas e na importância das disciplinas para a atuação profissional no mercado de trabalho. Os dados obtidos através desta pesquisa colaboram para a implementação das diretrizes pedagógicas da área e para o alinhamento das ações curriculares no curso de Relações Públicas da UFSM, podendo, a metodologia, ser adaptada para outras Instituições considerando a natureza e a cultura organizacional dos cursos. Para este estudo foram perfilados nove egressos, cada um correspondente a uma área de atuação, considerando que as áreas escolhidas dão suporte para as outras sete áreas. Além disso, a região de abrangência da Instituição de Ensino Superior, onde o projeto foi desenvolvido, não possui profissionais atuando em todas as áreas de atuação descritas pelo documento pedagógico. Dessa forma, os nove entrevistados formam uma amostra representativa capaz de gerar reflexões sobre o PPC do curso, bem como sobre as outras áreas.

Figura 02: Marca da vinheta de abertura do programa e entrevistadas da segunda temporada no estúdio de gravação localizado no campus da UFSM.

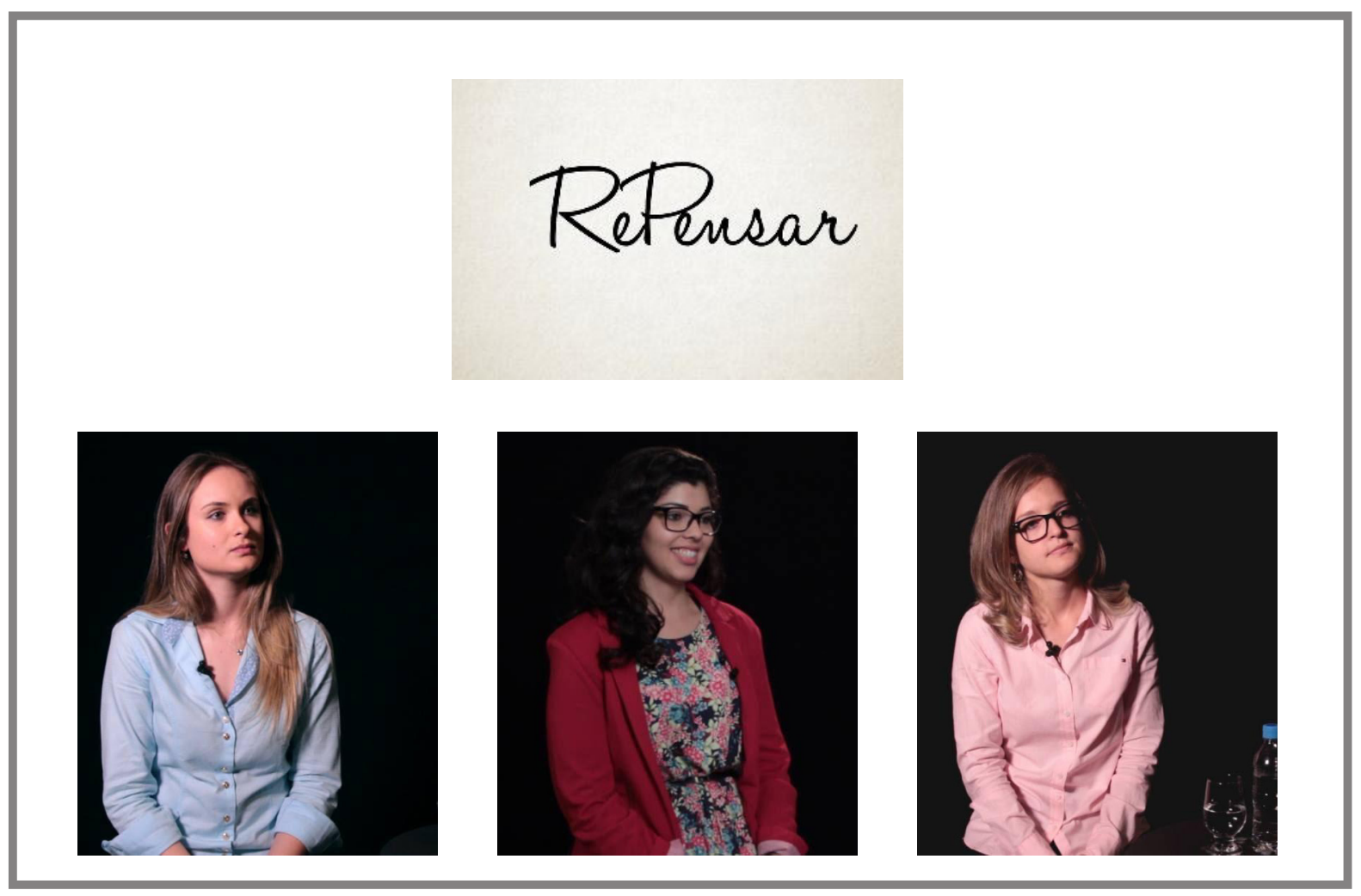

As entrevistas em vídeo realizadas no projeto permitiram que o entrevistado decidisse como construir a resposta, sendo esta uma entrevista não estruturada. Trabalhar com entrevistas não estruturadas possibilita "o desenvolvimento de conceitos e esclarecimento de situações, atitudes e com- 
portamentos ou o enriquecimento do significado humano deles (...) geração de teorias e decisões práticas" (MATTOS apud GODOI et al, 2010, p. 348) que neste projeto foram utilizadas para servir como fonte de conteúdo para repensar o fazer pedagógico das Relações Públicas. Com base nos métodos apresentados pelo autor, o entrevistador se faz oculto e o personagem principal (para quem as câmeras se voltam), o entrevistado, é o detentor do objeto de interesse: as respostas relatadas na cena. Para MATTOS apud GODOI et al (2010, p. 350) através dos relatos e do decorrer da entrevista salta-se "legitimamente da fala de um entrevistado, (...) ou vários deles, para um significado interpretativo" com o objetivo de "organizar as informações resultantes das entrevistas para gerar resultados". A interpretação desses relatos se reproduz "com o auxílio de uma linguagem precisa, uma compreensão própria, estruturada e estável da realidade" que é realizada pelo entrevistador, produzindo uma leitura e interpretação consciente e útil.

Segundo os conceitos de singularidade nas entrevistas, estabelecidos pelos autores acima citados, afirma-se que cada entrevista realizada no projeto foi singular, pois cada uma foi referente a uma área de atuação específica, gerando resultados também específicos. Por mais que o processo da entrevista tenho sido planejado e pensado previamente, cada uma gerou um diálogo espontâneo. Esses permitem que a exploração do conteúdo seja feita de maneira distinta em todos os casos, havendo tomadas de turno, já que esses são mecanismos-chave para a organização estrutural da conversação.

Numa primeira visada para os lugares que as Relações Públicas ocupam, observa-se um território polissêmico habitado por diferentes sujeitos e com múltiplas vozes. Por isso o mapeamento das áreas de atuação com a finalidade de cercar os sentidos plurais que circulam no fazer profissional deve indicar os modelos pedagógicos adotados pela academia. Entre as áreas de atuação mais exercidas pelos Relações Públicas egressos da UFSM na região geográfica de abrangência da Instituição estão: Planejamento de eventos; Planejamento de estratégias de comunicação de empresas privadas; Assessoria de comunicação/imprensa; Planejamento e produção de peças gráficas; Gerenciamento da imagem empresarial. Considerando as diferentes matrizes curriculares e tendo como ponto de partida os espaços de atuação dos profissionais, ficou estabelecida a seguinte amostra: 
Tabela 03 - Mapa descritivo dos perfis e das áreas de atuação da amostra selecionada para entrevista.

\begin{tabular}{|c|c|c|}
\hline & Currículo de 1987 & \\
\hline Egresso & Perfil profissional & Área de atuação \\
\hline $\mathrm{A}$ & $\begin{array}{l}\text { Sexo feminino. Formada em Relações Públicas pela } \\
\text { Universidade Federal de Santa Maria. Atualmente tra- } \\
\text { balha na empresa Sicredi - Instituição bancária. }\end{array}$ & $\begin{array}{l}\text { Planejamento de es- } \\
\text { tratégias de comuni- } \\
\text { cação de empresas } \\
\text { privadas. }\end{array}$ \\
\hline B & $\begin{array}{l}\text { Sexo Masculino. Formado em Relações Públicas pela } \\
\text { Universidade Federal de Santa Maria. Já atuou como } \\
\text { Produtor Cultural na empresa Cida Planejamento Cul- } \\
\text { tural e foi Relações Públicas do Theatro Treze de Maio } \\
\text { de Santa Maria, onde ainda atua como Assessor de } \\
\text { Projetos Culturais. Atuou como assessor de Relações } \\
\text { Públicas da Orquestra Sinfônica de Santa Maria. Foi } \\
\text { Professor Substituto nos Cursos de Comunicação So- } \\
\text { cial da Universidade Federal de Santa Maria. Também } \\
\text { foi colunista interino do Jornal Diário de Santa Maria. } \\
\text { Ministra palestra e oficinas com o tema Produção Cul- } \\
\text { tural. Atualmente é Secretário Adjunto da Secretaria de } \\
\text { Município de Cultura da Prefeitura Municipal de Santa } \\
\text { Maria RS e também trabalha como gestor na área de } \\
\text { Planejamento de eventos. }\end{array}$ & \begin{tabular}{|l} 
Planejamento de \\
eventos. \\
\\
\end{tabular} \\
\hline \multirow[t]{2}{*}{ C } & $\begin{array}{l}\text { Sexo feminino. Formada em Relações Públicas pela } \\
\text { Universidade Federal de Santa Maria. Atualmente é } \\
\text { proprietária de uma empresa de produção cultural em } \\
\text { Santa Maria. Empreendedora cultural. }\end{array}$ & $\begin{array}{l}\text { Gestão de projetos } \\
\text { culturais. }\end{array}$ \\
\hline & Currículo de 2004 & \\
\hline $\mathrm{D}$ & $\begin{array}{l}\text { Sexo feminino. Formada em Relações Públicas pela } \\
\text { Universidade Federal de Santa Maria e graduada em } \\
\text { Turismo, pelo Centro Universitário Franciscano. É Espe- } \\
\text { cialista em Comunicação e projetos de Mídia, pelo Cen- } \\
\text { tro Universitário Franciscano e possui MBA em Gestão } \\
\text { Empresarial pela Universidade de Santa Cruz do Sul. } \\
\text { Atualmente, é Analista Legislativo - área Relações } \\
\text { Públicas na Câmara Municipal de Vereadores de Santa } \\
\text { Maria. }\end{array}$ & $\begin{array}{l}\text { Planejamento de es- } \\
\text { tratégias de comuni- } \\
\text { cação de empresas } \\
\text { governamentais. }\end{array}$ \\
\hline $\mathrm{E}$ & $\begin{array}{l}\text { Sexo feminino. Formada em Relações Públicas pela } \\
\text { Universidade Federal de Santa Maria. É servidora } \\
\text { pública no Instituto Federal Farroupilha e atua como } \\
\text { diagramadora. }\end{array}$ & $\begin{array}{l}\text { Planejamento e pro- } \\
\text { dução de peças gráfi- } \\
\text { cas. }\end{array}$ \\
\hline
\end{tabular}




\begin{tabular}{|c|c|c|}
\hline $\mathrm{F}$ & $\begin{array}{l}\text { Sexo feminino. Formada em Relações Públicas pela } \\
\text { Universidade Federal de Santa Maria e graduação } \\
\text { em Turismo pelo Centro Universitário Franciscano. } \\
\text { Pós-graduada em nível de especialização em MBA em } \\
\text { Marketing Estratégico pela Universidade do Vale do } \\
\text { Itajaí. Participa como voluntária do Grupo de Pesquisa } \\
\text { Estudos e Pesquisas em Estratégia, Inovação e Suste- } \\
\text { ntabilidade. Compõe a diretoria da Associação de Jov- } \\
\text { ens Empreendedores de Santa Maria (RS). Atualmente } \\
\text { é sócia-proprietária de uma empresa de Turismo. }\end{array}$ & $\begin{array}{l}\text { Assessoria e con- } \\
\text { sultoria de comuni- } \\
\text { cação. }\end{array}$ \\
\hline \multicolumn{3}{|c|}{ Currículo de 2010} \\
\hline G & $\begin{array}{l}\text { Sexo feminino. Formada em Relaçães Públicas pela } \\
\text { Universidade Federal de Santa Maria. Cursa MBA } \\
\text { em Mídias Sociais Digitais pelo Centro Universitário } \\
\text { Franciscano e é Aluna Especial do Mestrado em Co- } \\
\text { municação Midiática da UFSM. Tem experiência nas } \\
\text { seguintes áreas: fotografia, produção audiovisual, } \\
\text { assessoria e consultoria de Relações Públicas, plane- } \\
\text { jamento de comunicação e organização de eventos. } \\
\text { Atua principalmente como fotografia em eventos soci- } \\
\text { ais e corporativos. }\end{array}$ & $\begin{array}{l}\text { Planejamento e pro- } \\
\text { dução de fotos. }\end{array}$ \\
\hline $\mathrm{H}$ & $\begin{array}{l}\text { Sexo feminino. Formada em Relações Públicas pela } \\
\text { Universidade Federal de Santa Maria. Atualmente atua } \\
\text { no Lar das Vovozinhas, Organização Sem Fins Lucrati- } \\
\text { vos que abriga idosas em Santa Maria. }\end{array}$ & $\begin{array}{l}\text { Planejamento de es- } \\
\text { tratégias de comuni- } \\
\text { cação de empresas } \\
\text { do Terceiro Setor. }\end{array}$ \\
\hline I & $\begin{array}{l}\text { Sexo feminino. Formada em Relações Públicas pela } \\
\text { Universidade Federal de Santa Maria UFSM. Mestre em } \\
\text { Comunicação Midiática e Doutoranda do Programa de } \\
\text { Pós-Graduação em Comunicação da Universidade Fed- } \\
\text { eral de Santa Maria. É integrante do grupo de pesquisa } \\
\text { Comunicação Institucional e Organizacional, vinculado } \\
\text { ao CNPq. Pesquisa nas áreas de comunicação midiáti- } \\
\text { ca, comunicação para a cidadania e estratégias discur- } \\
\text { sivas. }\end{array}$ & $\begin{array}{l}\text { Pesquisador científi- } \\
\text { co na área da comu- } \\
\text { nicação. }\end{array}$ \\
\hline
\end{tabular}

Os profissionais que relataram suas memórias e compartilharam suas expectativas com a profissão fazem parte de grupos de saberes que negociaram experiências singulares. Estudos de BARICHELO (2001), MOURA (2002) e SILVEIRA (2003), apenas para citar alguns, já discutiram as implicações históricas da formação curricular em comunicação Social e em Relações Públicas, enfatizando especialmente o curso da Universidade Federal de Santa Maria. A contribuição destas pesquisas para o texto em discussão é a proposta de avanço através da análise do comportamento dos egressos no mercado de trabalho, além dos acionamentos e das interações oriundas do conhecimento adquirido na academia e da manutenção do vínculo com a 
Instituição formadora desses sujeitos sociais.

Foi diagnosticado que as áreas de atuação dos profissionais de Relações Públicas decorre das relações que ele constrói enquanto aluno. A porta de entrada em uma profissão desconhecida leva ao abandono da mesma ainda no percurso da formação, como é percebido entre os anos de 1990 e 1994, durante a vigência da matriz curricular 1987 que perdurou por dezesseis anos. A virada nos números de abandono e transferências se dá com a implantação do programa de extensão "Universidade e Comunidade" que implantou assessorias de comunicação nas Unidades de Ensino da Instituição. Esse movimento aproximou a realidade da comunicação aos eixos das relações públicas, provocando a transversalidade dos saberes. Assim, houve uma aproximação das áreas - comunicação e relações públicas - e a atuação da prática profissional pode ser experimentada na dinâmica midiática. Para SILVERSTONE (2005), "a experiência é moldada, ordenada e interrompida. É moldada por atividades e experiências prévias. É ordenada de acordo com normas e classificações que resistem à prova do tempo e do social. É interrompida pelo inesperado, pelo não preparado (...)" (p.28). O gráfico abaixo mostra a dinâmica da experiência de encontro com o campo midiático através da inclusão de rotinas extensionistas:

Gráfico 01: Dados dos alunos egressos no período de 1990 a 2003 do Curso de Comunicação Social - Relações Públicas da UFSM.

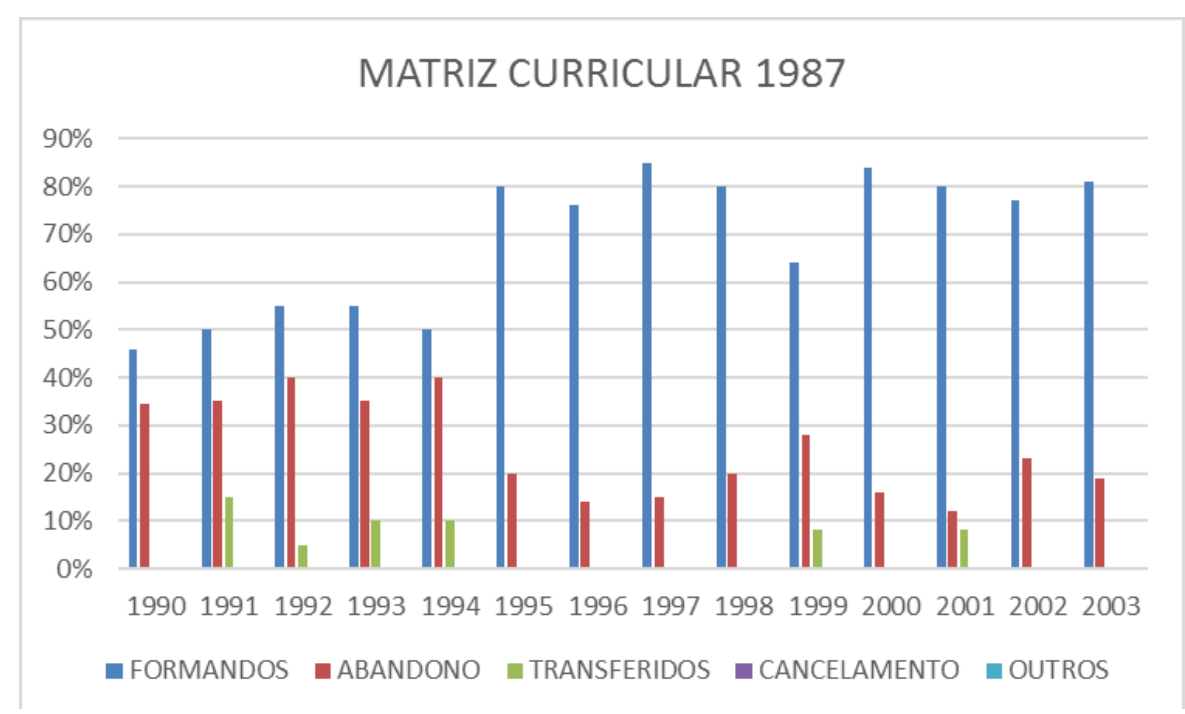

A necessidade de sistematização das rotinas em documentos pedagógicos e a observância das diretrizes curriculares conduz a primeira alteração curricular depois de quase 20 anos de formação de profissionais de Rela- 
ções Públicas pela Universidade pública e interiorana. A confiança dada pela consolidação das práticas pedagógicas equaliza a expectativa da entrada no lugar acadêmico com a esperança da saída para o mercado profissional. Seguindo com SILVERSTONE,

para a maioria de nós, na maior parte do tempo, a atitude natural do mundo dado-por-certo é aquela que nos permite manter nossa sanidade na passagem pela vida e pelo dia-a-dia. Rotinas, hábitos, reforços cognitivos e emocionais, continuamente reafirmados, as seguranças (muitas vezes ritualizadas) de nossa passagem pelo tempo e pelo espaço, e as consistências com que nossas expectativas fornecem, juntos, a infra-estrutura para um universo moral em que nós, seus cidadãos, podemos levar a cabo nossas atividades cotidianas. (2005, p.220)

A segurança para atuar na área de Relações Públicas requer o trabalho contínuo de vigilância pelos gestores pedagógicos. A queda do número de formandos da turma de 2007 aponta para um espaço de negociação encurtado em relação aos períodos curriculares anteriores e força a entrada de novos projetos de experimentação - tanta em extensão como em pesquisa, que desencadeiam uma outra versão da matriz curricular. É possível observar que em 2008 e em 2009 com a consolidação do programa de Pós-Graduação em Comunicação há uma investida nas perspectivas de atuação do acadêmico e força o aumento no número de concluintes na graduação em Relações Públicas. É possível verificar esses dados na comparação entre os dois gráficos das matrizes curriculares de 2004 e de 2010:

Gráfico 02: Dados dos alunos egressos no período de 2004 a 2009 do Curso de Comunicação Social - Relações Públicas da UFSM.

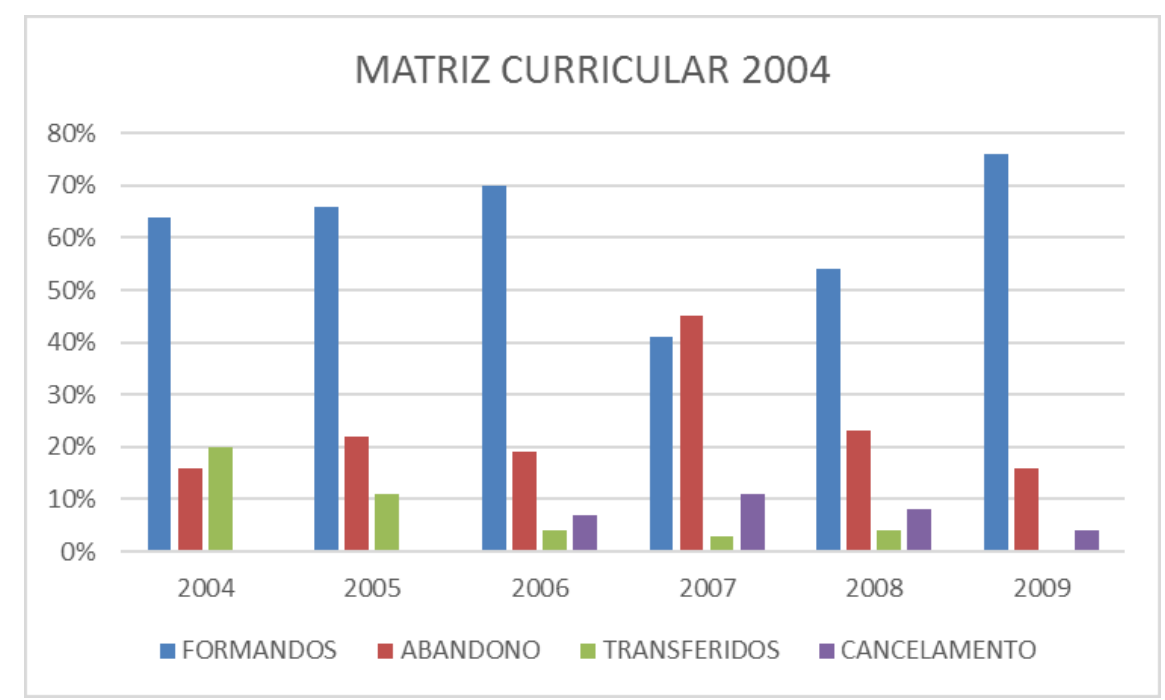


Gráfico 03: Dados dos alunos egressos nos anos de 2010 e 2011 do Curso de Comunicação Social - Relações Públicas da UFSM.

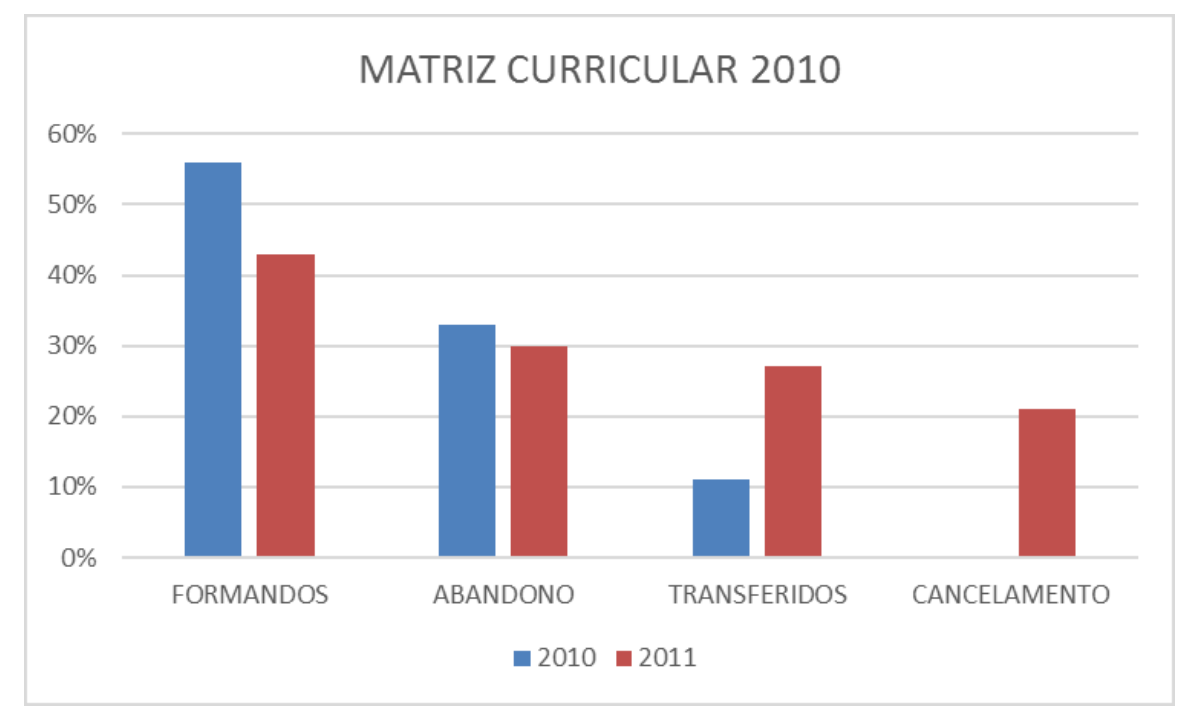

Assim posto, verifica-se que a implementação dos saberes e a abertura para experiências complementares que ao quebrar o linearismo da vertente curricular impulsionam a redescoberta do poder das relações públicas na cena midiática, legitimando-a no interior do campo da comunicação como área de investigação e de atuação profissional em diferentes mercados - local, regional, nacional e internacional.

\section{OS SENTIDOS E AS MARCAS DO EMPODERAMENTO NAS ÁREAS DE ATUAÇÃO: A CONTRIBUIÇÃO DOS EGRESSOS NA FORMAÇÃO DAS AÇÕES PEDAGÓGICAS}

Após o mapeamento das áreas de atuação e das práticas profissionais entre os egressos da região de abrangência da UFSM foram categorizadas as disciplinas que cada profissional julgou fundamental para seu campo de competência. É importante destacar que os alinhamentos das áreas de conhecimento fazem parte da construção de um currículo básico e que serve como suporte estruturante para as demandas no mercado de trabalho. Por isso, o empoderamento do profissional em formação é determinante para a abertura das áreas de atuação no mercado emergente local e regional.

O empoderamento de sujeitos, indivíduos e organizações ainda apresenta conceituação ambígua e é definido através de diferentes enfoques na literatura. Interessa para este recorte teórico metodológico o empoderamento individual e o organizacional porque apontam saídas no planejamento pedagógico para a ação das Relações Públicas. O empoderamento individual é uma auto-emancipação, como explicam FREIRE e SHOR (1986), fundada 
numa compreensão individualista de empoderamento e que enfatiza a dimensão psicossocial. Segundo essa lógica, deve-se aumentar o poder individual, aumentando o nível de autoestima, de autoafirmação e de autoconfiança das pessoas. As estratégias de autoaperfeiçoamento estão presentes neste tipo de empoderamento e podem ser percebidas nas entrevistas com os profissionais quando apontaram poucas disciplinas especificas no curso de graduação que contemplassem sua área de atuação. Segundo eles, foi necessário buscar fora do próprio curso elementos que faziam parte da base fundamental para a formação do profissional. Para a entrevistada que atua na área de planejamento de estratégias de comunicação em empresas privadas foi sentido que deveriam "ter atividades extras (...) que a gente pudesse ter um pouquinho mais de aperfeiçoamento, mais foco no mercado, um pouquinho mais de experiência antes de sair do curso".

O ponto de convergência entre mercado e academia é relatado pela experiência adquirida ao longo da formação e que tem efetivamente empoderado os profissionais na disputa dos lugares de atuação. Neste caso refere-se do empoderamento organizacional, ou seja, o poder gerado na e pela organização. Trata-se da delegação do poder de decisão, da autonomia e da participação do profissional, portanto o empoderamento organizacional significa "dar ao pessoal autoridade para fazer mudanças no trabalho em si, assim como na forma em que ele é desempenhado" (SLACK et. al. 1997, p. 311). A entrevistada que atua em Gestão de projetos culturais se refere a todo conhecimento gerado por e para ela, ou seja, "tudo que a gente trabalhou a gente vai usando de uma forma ou outra, tudo vai te valendo. (...) Na tua profissão que tu vai achando o teu diferencial também para trabalhar, porque quando eu comecei a trabalhar na área não tinha muita gente na área. Hoje tem bastante, (...) então o teu diferencial é quanto mais tu tem de conhecimento".

Deste rápido recorte vislumbra-se que o lugar de empoderamento dos sentidos das relações públicas é a academia. Por isso o objetivo primeiro das ações pedagógicas e da construção das matrizes curriculares deve passar pela revisão das ordens hierárquicas de saberes: o teórico e o prático. $\mathrm{O}$ poder dado ao profissional em formação não reside no núcleo de formação ou no núcleo específico, mas na relação estável entre ambos e na construção de redes de saberes que possibilitam o exercício da profissão. Para a entrevistada que atua em assessoria e consultoria de comunicação "a teoria é extremamente importante, eu sou uma eterna defensora de tu conseguir 
aliar a teoria com a prática (...) só com a teoria infelizmente a gente não tem condições de fazer um bom trabalho no mercado".

Destacou-se também a importância do papel do docente na construção do conhecimento para o mercado de trabalho. A entrevistada que atua na área de assessoria e consultoria de comunicação afirmou que "nós tivemos professores excelentes durante a graduação (...), no entanto, faltou mais a prática. Faltou professores que tivessem mais experiência no mercado. A partir do momento que tu trás as tuas experiências, exemplos práticos, tu facilita a compreensão dos conceitos". Já a Relações Públicas que atua como pesquisadora científica na área da comunicação afirmou que é importante a aproximação com o mercado, segundo ela, "eu entendo a importância (...) de fazer esse vínculo com o mercado (...) para a atualização das técnicas de relações públicas (...) principalmente por eu não ter essa experiência de mercado que muitas vezes me é cobrada dentro de sala de aula". Também relatou que durante sua graduação em uma disciplina de audiovisual, ajudou "muito o fato de o professor ter experiência porque ele conseguia trazer exemplos do cotidiano dele, conseguia contextualizar os conteúdos, trazia inclusive VT's que ele mesmo produziu isso era muito legal". Observa-se que por mais que os profissionais necessitem de experiências práticas, os mesmos não anulam as disciplinas teóricas e inclusive destacam as fundamentais para a formação profissional e ética.

Assim, com essas rápidas anotações das falas dos profissionais egressos verificam-se alinhamentos de sentidos que orientam as ações pedagógicas no entendimento das áreas de atuação:

1. $O$ ingressante desconhece a profissão de Relações Públicas - não há um entendimento claro do que faz o profissional e qual suas competências frente às outras áreas da Comunicação;

2. Dicotomia entre a prática e a teoria - ao optar pelo curso de Relações Públicas o acadêmico não relaciona os eixos práticos e teóricos que o preparam para o mercado de trabalho;

3. Distanciamento do habilitado (para) e da competência (para) - as matrizes curriculares ainda seguem a lógica da habilitação, esvaziando o sentido da profissão de Relações Públicas;

4. Legitimação das Relações Públicas no campo da comunicação - a área de Relações Públicas deve investir no espaço científico aberto pelo campo comunicacional, consolidando suas práticas no ambiente midiático;

5. Empoderamento dos atores sociais na área de Relações Públicas - 
empoderar alunos, professores e profissionais a partir de suas áreas de atuação, assegurando a interação entre o pedagógico e o profissional.

Entende-se, portanto, que a convergência entre mercado e academia se estabelece quando o profissional e o acadêmico compreendem seus espaços. A academia como centro formador, possibilitando uma base completa de conhecimento e oportunidades e o mercado como aplicação das práticas estudadas, abrindo portas para o aperfeiçoamento e o desenvolvimento de novos processos de comunicação.

\section{REFERÊNCIAS}

BARICHELLO, Eugenia M. Comunicação e Comunidade do Saber. Santa Maria: Palotti, 2001.

CHAUI, Marilena. Convite à Filosofia. São Paulo: Ática, 2008.

FERRARI, Maria A. Relações Públicas: razões para praticá-las. São Paulo, Revista Organicom, 2009.

FREIRE, Paulo; SHOR, Ira. Medo e ousadia - o cotidiano do professor. Rio de Janeiro: Paz e Terra, 1986.

HABERMAS, J. Mudança Estrutural da esfera pública. Rio de Janeiro: TB, 1984.

KOCH, I. G. V. A inter-ação pela linguagem. $4^{a}$ ed. São Paulo: Contexto, 1998. (Repensando a língua portuguesa.)

MATTOS, P. L. C. L. Análise de entrevistas não estruturadas: da formalização à pragmática da linguagem. In: SILVA, A. B.; GODOI, C. K.; BANDEIRA-DE-MELO, R. (orgs). Pesquisa qualitativa em estudos organizacionais: paradigmas, estratégias e métodos. 2. ed. São Paulo, 2010, p. 347-374.

MOURA, P.M; SCROFERNEKER,C.M.A. Relações Públicas $x$ função política e administração de conflitos/controvérsias nas organizações. São Paulo, Revista Comunicação, Marketing,Cultura,1999.

MOURA, Cláudia. P. e FOSSATTI, Nelson C. Práticas Acadêmicas em Relações Públicas. Porto Alegre: Sulina, 2011

RÜDIGER, F. Relações Públicas e Pesquisa Crítica em Comunicação. In MOURA, Cláudia. P. e FOSSATTI, Nelson C. Práticas Acadêmicas em Relações Públicas. Porto Alegre: Sulina, 2011

SLACK, Nigel et. al. Administração da produção. São Paulo: Atlas, 1997.

SILVEIRA, Ada M. (org.) Práticas, identidade e memória: 30 anos de Relações Públicas na UFSM. Santa Maria: FACOS-UFSM, 2003.

SILVERSTONE, Roger. Por que Estudar a Mídia? São Paulo: Loyola, 2002. 


\section{Elisangela Carlosso Machado Mortari}

Docente do Departamento de Ciências da Comunicação da Universidade Federal de Santa Maria. Doutora em Comunicação e Cultura pela Universidade Federal do Rio de Janeiro. Graduada em Comunicação Social - Relações Públicas pela Universidade Federal de Santa Maria. Líder do Grupo de Pesquisa Comunicação e Discursos Sociais.

E-mail: elimortari@gmail.com

\section{Jozene Noal de Oliveira}

Acadêmica do Curso de Comunicação Social - Relações Públicas pela Universidade Federal de Santa Maria. Bolsista da Agência Experimental de Relações Públicas (AGERP). Integrante do projeto "RePensar: ações de avaliação em Relações Públicas.

E-mail: jozenenoal@hotmail.com 